\title{
COMPARISON OF MORTALITY BETWEEN THE COMBINATION OF STANDARD THERAPY AND CONVALESCENT PLASMA THERAPY AND STANDARD THERAPY ONLY IN COVID-19 PATIENTS: SYSTEMATIC REVIEW AND META- ANALYSIS
}

\author{
Felicia Klarin ${ }^{1}$, Angelica Diana Vita*1®, Cynthia Elvira Sari Siahaan ${ }^{1}$, Salsabila \\ Nabilah Rifdah ${ }^{1}$, Ayu Rahmanita Putri ${ }^{1}$, Indriasti Putri Kusuma ${ }^{1}$, Subur Prayitno ${ }^{2}$ \\ ${ }^{1}$ Faculty of Medicine, Universitas Airlangga, Surabaya, Indonesia \\ ${ }^{2}$ Department of Community Medicine and Preventive Health, Faculty of Medicine, Universitas Airlangga, \\ Surabaya, Indonesia
}

\section{ABSTRACT}

Coronavirus Disease-19 (COVID-19) is an infectious disease caused by a newly discovered type of coronavirus. Comprehensive management for COVID-19 patients includes infection control, hemodynamic stability maintenance, oxygenation monitoring, ventilation, and pharmacotherapy administration. Convalescent plasma is one of the COVID-19 therapy choices, proven to provide relief for Ebola, SARS, and MERS patients. Therefore, the authors believed in searching data on whether convalescent plasma therapy also improves COVID-19 patients, specifically in terms of mortality. This study aims to compare the comparison in mortality between standard therapy and convalescent plasma therapy with standard therapy only in COVID-19 patients. This study used a systematic review and meta-analysis method according to the Preferred Reporting Items for Systematic Reviews and MetaAnalysis (PRISMA) guidelines. This study used ten studies that met the inclusion criteria to evaluate the comparison in mortality between the combination therapy with standard therapy only in COVID-19 patients. There was a significant difference in mortality between the combination of standard therapy and convalescent plasma therapy with standard therapy only in COVID-19 patients, and mortality in the combination therapy groups being lower than standard therapy only.
\end{abstract}

\section{ARTICLE HISTORY}

Received: July 1, 2021

Revised: August 10, 2021

Accepted: August 31, 2021

Published: October 31, 2021

(Online)

doi:

10.20473/jcmphr.v2i2.27432

\section{KEYWORDS}

COVID-19; convalescent plasma; mortality; public health

\section{CORRESPONDING AUTHOR}

Angelica Diana Vita

$\triangle$ angelicadiana777@gmail.com Faculty of Medicine, Universitas Airlangga, Jl. Mayjend Prof. Dr. Moestopo 47, Surabaya, Indonesia

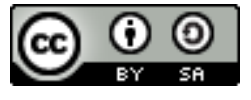

\section{INTRODUCTION}

Coronavirus Disease-19 (COVID-19) is an infectious disease caused by a newly discovered type of coronavirus, namely the beta coronavirus. Currently known as SARSCoV-2, it appeared as an outbreak in Wuhan, Hubei Province, China, in December 2019. WHO declared COVID-19 was a global pandemic on March 11, 2020. ${ }^{1}$ COVID-19 primarily attacks the respiratory system, but symptoms in other organ systems can also be identified. Some studies suggest that this disease has two pathogenesis, namely high viral replication in the early course of the disease and the presence of patient's immune system dysregulation. ${ }^{2}$

Convalescent plasma therapy is one of the COVID-19 therapy modalities currently studied in the clinical trial stage. This therapy works by passively transferring antibodies from COVID-19 patients who have recovered to patients who have severe symptoms or potentially life-threatening patients due to COVID-19 infections. This 
therapy aims to reduce the death rate with the presence of specific antibodies. The use of convalescent plasma therapy during pandemics has been shown to provide recovery in Ebola, SARS, and MERS patients. However, the dosage and effectiveness of convalescent plasma therapy given in various countries still vary widely until now. ${ }^{3}$ Therefore, the authors believed it is crucial to search data regarding the improvements that convalescent plasma therapy brought for COVID-19 patients, especially clinical improvement after administration. ${ }^{4}$

\section{MATERIALS AND METHODS}

This study analyzed several journals with a systematic review and meta-analysis method based on randomized control trials, clinical trials, case controls, and analytic cohort studies regarding comparative studies between two independent sample groups. The groups compared were a sample group of COVID-19 patients who received the combination of standard therapy and convalescent plasma therapy and a sample group of COVID-19 patients who received standard therapy only. This research was analyzed in a table with the narrative review, forest plot, and funnel plot. The inclusion criteria were as follows: infected by COVID19 and confirmed by PCR test, having moderate to severe symptoms of COVID-19 infection, and had mortality data included in the study. The criteria of this study were as follows: journals written in languages other than English, full-texts were not included, other alternative treatments were included, ongoing or unfinished clinical trial studies, patients under 18 years old, pregnant, or breastfeeding.

Data collected in this study were based on ten scientific papers published in Englishlanguage international journals. Literature research for articles was carried out using several search engines such as Pubmed and ScienceDirect and focused on the keywords ("plasma therapy" OR "convalescent plasma") AND ("COVID-19" OR "SarsCov-2") AND ("mortality" OR "death"). The samples used in this study were 2 RCTs, 2 clinical trials, 5 analytic cohorts, 1 casecontrol with a total of 372 research subjects from Pubmed and ScienceDirect. The collected data were managed using the PRISMA (Preferred Reporting Items for Systematic Review and Meta-Analysis) method.

\section{RESULTS}

There were three duplicated articles, 1 article was not written in English, and 1 article failed to be accessed among 372 research articles found during the literature search process, which remains 367 articles for the next step screening. The 351 articles were eliminated through title and abstract relevance screening, which remains 16 articles for feasibility determination according to inclusion and exclusion criteria. One article was then excluded due to the outcome parameter used, and another five were excluded due to the control group. As a final result of literature selection, ten articles met the inclusion criteria and were eligible for this systematic review. Literature appraisal using Quality Assessment Tool for Quantitative Studies from EPHPP (Effective Public Health Practice Project) resulted in 8 strong articles and two moderate articles. Each article was evaluated according to 6 main components: selection bias, study design, confounders, blinding, data collection method, and withdrawal dropouts. Data extraction was done by filling a form as shown in Table 1, which consisted of author name, publication year, literature title, research location, study design, time frame, and results regarding mortality. 
Table 1. Data extraction

\begin{tabular}{|c|c|c|c|c|c|}
\hline Author & Article Title & Location & Study design & Time frame & Mortality results \\
\hline $\begin{array}{l}\mathrm{Li} \text { et al., } \\
2020^{5}\end{array}$ & $\begin{array}{l}\text { Effect of Convalescent Plasma } \\
\text { Therapy on Time to Clinical } \\
\text { Improvement in Patients with } \\
\text { Severe and Life-threatening } \\
\text { COVID-19: A Randomized } \\
\text { Clinical Trial }\end{array}$ & $\begin{array}{l}\text { Wuhan, } \\
\text { China }\end{array}$ & $\begin{array}{l}\text { Randomised } \\
\text { Controlled } \\
\text { Trial }\end{array}$ & $\begin{array}{l}14 \text { February - } \\
1 \text { April } 2020\end{array}$ & $\begin{array}{l}\text { There was no significant } \\
\text { difference in the secondary } \\
\text { outcome of } 28 \text {-day mortality } \\
\text { ( } 15.7 \% \text { in the convalescent } \\
\text { plasma group vs } 24.0 \% \text { in the } \\
\text { control group; OR, } 0.59 \text { [95\% } \\
\text { CI, } 0.22-1.59 \text { ]; } P=0.30)\end{array}$ \\
\hline
\end{tabular}

Progression to severe disease or all cause mortality at 28 days after enrolment occurred

Convalescent plasma in the management of moderate covid-19 Argawal et in adults in India: open label phase al., $2020^{6}$ II multicentre randomised controlled trial (PLACID Trial)
Controlled Trial
22 April - 14 July 2020 in $44(19 \%)$ participants in the intervention arm and 41 $(18 \%)$ in the control arm (risk difference $\quad 0.008 \quad(95 \%$ confidence interval -0.062 to 0.078 ); risk ratio $1.04,95 \%$ confidence interval 0.71 to 1.54). Administration of convalescent plasma therapy has no significant difference.

Convalescent plasma substantially reduced all-

Abolghase mi et al. $2020^{7}$

Clinical efficacy of convalescent plasma for treatment of COVID-19 infections: Results of a multicenter clinical study

\section{Non}

Iran

randomised

clinical trial
March - April 2020 cause mortality in the treatment group compared with the control group (14.8\% vs $24.3 \%$ ). However, this was not statistically different.

In general, 21 patients $(32.8 \%)$ including 7 in the plasma group and 14 in the control group died. While the number of recovered patients were higher in the plasma group in comparison with the control group, there was no

Efficacy and safety of

Allahyari convalescent plasma therapy in

et al., severe COVID-19 patients with

$2021^{8}$ acute respiratory distress syndrome
Mashhad Clinical trial , Iran parallel study
21 April - 31

May 2020

Last follow up on 27 June 2020 statistically significant difference between the two groups $(\mathrm{p}=0.062)$. Propensity score calculations showed a $\mathrm{p}$ value of $\leq 0.001$ (Odds Ratio (OR): $\quad 1.30$, with $95 \%$ Confidence Interval (CI) from 1.13 to 1.49 ) indicating that the odds of death in the control group was $30 \%$ higher compared to the plasma group.

The 28-day mortality rate was $25.48 \%$ in plasma

13 April - 7

July 2020

(plasma group) 15 March 19 July 2020 (control group) convalescent cases and $27 \%$ in controls $(P=0.06)$, which shows no statistical difference. The 7-day adjusted mortality rate was statistically different between the two groups and was lower in CCP cases $(9.13 \%)$ compared to controls $(19.77 \%)(P<0.001)$ with an $10.64 \%$ absolute reduction.

Analytic
cohort matched control study
USA 


\begin{tabular}{|c|c|c|c|c|}
\hline \multirow{8}{*}{$\begin{array}{l}\text { Salazar et } \\
\text { al., } 2021^{10}\end{array}$} & Significantly Decreased Mortality & \multirow{8}{*}{$\begin{array}{l}\text { Texas, } \\
\text { USA }\end{array}$} & \multirow{8}{*}{ Cohort } & \multirow{8}{*}{$\begin{array}{l}28 \text { March - } \\
\text { 14 September } \\
2020\end{array}$} \\
\hline & $\begin{array}{l}\text { in a Large Cohort of Coronavirus } \\
\text { Disease } 2019 \quad \text { (COVID-19) }\end{array}$ & & & \\
\hline & Patients Transfused Early with & & & \\
\hline & Convalescent Plasma Containing & & & \\
\hline & High-Titer Anti-Severe Acute & & & \\
\hline & Respiratory & & & \\
\hline & Coronavirus 2 (SARS-CoV-2) & & & \\
\hline & Spike Protein IgG & & & \\
\hline
\end{tabular}

Alsharidah COVID-19 convalescent plasma et al treatment of moderate and severe $2021^{11}$., cases of SARS-CoV-2 infection: A multicenter interventional study

$\begin{array}{lll}\text { Kuwait } & \begin{array}{l}\text { Non- } \\ \text { randomized } \\ \text { prospective } \\ \text { cohort study }\end{array} & \text { 21 May - 30 2020 } \\ & \end{array}$

Convalescent plasma treatment is Tworek et associated with lower mortality al., $2021^{12}$ and better outcomes in high-risk COVID-19 patients - propensityscore matched case-control study
Warsaw, Prospective 24 April - 28

Poland observational September cohort 2020

The 14-day adjusted mortality continued to be statistically significant, with a mortality rate of $14.83 \%$ for CCP cases and $23.57 \%$ for the controls $(P=0.01)$ with an $8.74 \%$ absolute reduction

Overall mortality within 28 days is $12(3.7 \%)$ in the group transfused with convalescent plasma and $57(9,8 \%)$ in the control group, $\mathrm{p}=0,001$ $95 \%$ CI 2.62 (1.46 to 4.70 ).

In this prospective

interventional study including patients with moderate and severe COVID-19, CCP administration was significantly associated with improved clinical outcomes. Thirty-day survival was significantly improved in the moderate group $(\mathrm{P}=0,001 \mathrm{CI}$ $0.27(0.12-0.62))$. In addition, administration of CCP in both moderate and severe cases was also associated with improved oxygen saturation, and recovery of lymphocytes and CRP levels.

Findings confirmed a significantly lower mortality rate in the $\mathrm{PG}$ versus the $\mathrm{CG}$ ( $13.7 \%$ vs. $34.3 \%, p=0.001)$ and a significant difference in the cumulative incidence of death between the two groups (p <0.001). CP treatment was associated with lower risk of death $(\mathrm{OR}=0.25$ CI95[0.06; $0.91], p=0.041$ ).

In the overall group of 1079 patients, mortality in plasma vs no plasma group was statistically not significant ( $22.4 \%$ vs $18.5 \%$; $\mathrm{p}=0.125$; $\mathrm{OR}=1.27,95 \%$ CI: 0.94 1.72). However, in patients with COVID-19 admitted to ICU, mortality was significantly lower in plasma

$\begin{array}{llll}\text { Budhiraja } & \text { Effectiveness of convalescent } & \text { New } & \begin{array}{l}\text { Retrospective } \\ \text { observational }\end{array} \text { 1 May - } 30 \\ \text { et al., } & \text { plasma in Indian patients with } \\ 2021^{13} & \text { COVID-19 } & \text { Delhi, } & \begin{array}{l}\text { case control August 2020 } \\ \text { study }\end{array}\end{array}$
group $(25.5 \%$ vs $33.2 \%$; $\mathrm{p}=$ $0.026 ;$ OR $=0.69,95 \%$ CI: $0.50-0.96)$. This benefit of reduced mortality was most seen in age group 60 to 74 years $(26.7 \%$ vs $43.0 \%$; p = $0.004 ;$ OR $=0.48,95 \%$ CI: $0.29-0.80$ ), driven mostly by females of this age group $(23.1 \%$ vs $53.5 \%$; $=0.013$; $\mathrm{OR}=0.26,95 \%$ CI: 0.09 0.78 ). Significant difference in mortality was observed in 


\begin{tabular}{|c|c|c|c|c|c|}
\hline $\begin{array}{l}\text { Salazar et } \\
\text { al., } 2020^{14}\end{array}$ & $\begin{array}{l}\text { Treatment of Coronavirus Disease } \\
2019 \text { Patients with Convalescent } \\
\text { Plasma Reveals a Signal of } \\
\text { Significantly Decreased Mortality }\end{array}$ & $\begin{array}{l}\text { Houston, } \\
\text { Texas, } \\
\text { US }\end{array}$ & $\begin{array}{l}\text { Prospective } \\
\text { cohort }\end{array}$ & $\begin{array}{lr}28 & \text { March } \\
2020 & -6 \text { July } \\
2020 & \end{array}$ & $\begin{array}{l}\text { days, specifically in patients } \\
\text { transfused within } 72 \text { hours of } \\
\text { admission with plasma with } \\
\text { an anti-spike protein receptor } \\
\text { binding domain titer of } \\
\geq 1: 1350 \text {. }\end{array}$ \\
\hline
\end{tabular}

\begin{tabular}{|c|c|c|c|c|c|c|c|c|c|}
\hline \multirow[b]{2}{*}{ Study or Subgroup } & \multicolumn{2}{|c|}{ Terapi standar + Plasma } & \multicolumn{2}{|c|}{ Terapi standar } & \multicolumn{2}{|r|}{ Risk Ratio } & \multirow{2}{*}{\multicolumn{2}{|c|}{$\begin{array}{c}\text { Risk Ratio } \\
\text { M-H, Random, } 95 \% \mathrm{Cl}\end{array}$}} & \\
\hline & Events & Total & Events & Total & Weight & M-H, Random, $95 \% \mathrm{Cl}$ & & & \\
\hline Abolghasemi et al., 2020 & 17 & 115 & 18 & 74 & $8.6 \%$ & $0.61[0.34,1.10]$ & & & \\
\hline Agarwal et al., 2020 & 44 & 235 & 41 & 229 & $12.7 \%$ & $1.05[0.71,1.54]$ & & & \\
\hline Allahyari et al., 2021 & 7 & 32 & 14 & 32 & $6.3 \%$ & $0.50[0.23,1.07]$ & & & \\
\hline Alsharidah et al., 2021 & 24 & 135 & 90 & 233 & $12.4 \%$ & $0.46[0.31,0.68]$ & $\rightarrow$ & & \\
\hline Budhiraja et al., 2020 & 85 & 333 & 120 & 361 & $16.3 \%$ & $0.77[0.61,0.97]$ & $\rightarrow$ & & \\
\hline Li et al., 2020 & 8 & 51 & 12 & 50 & $5.8 \%$ & $0.65[0.29,1.46]$ & & & \\
\hline Salazar et al., 2020 & 20 & 321 & 73 & 582 & $10.7 \%$ & $0.50[0.31,0.80]$ & $\rightarrow$ & & \\
\hline Salazar et al., 2021 & 3 & 112 & 10 & 112 & $2.9 \%$ & $0.30[0.08,1.06]$ & & & \\
\hline Shenoy et al., 2021 & 67 & 263 & 71 & 263 & $15.1 \%$ & $0.94[0.71,1.26]$ & & & \\
\hline Tworek et al., 2021 & 14 & 102 & 35 & 102 & $9.2 \%$ & $0.40[0.23,0.70]$ & & & \\
\hline Total $(95 \% \mathrm{Cl})$ & & 1699 & & 2038 & $100.0 \%$ & $0.64[0.51,0.81]$ & $\Delta$ & & \\
\hline Total events & 289 & & 484 & & & & & & \\
\hline \multicolumn{7}{|c|}{$\begin{array}{l}\text { Heterogeneity: } \text { Tau }^{2}=0.07 ; C h i^{2}=22.03, d f=9(P=0.009) ; I^{2}=59 \% \\
\text { Test for overall effect: } Z=3.78(P=0.0002)\end{array}$} & 0.01 & 10 & 100 \\
\hline
\end{tabular}

Figure 1. Forest plot of all literature

The meta-analysis of this systematic review was done by Review Manager application 5.4.1 version. These ten articles compared COVID-19 therapy results between the intervention group (combination of standard therapy and convalescent plasma therapy) and the control group (standard therapy only). The forest plot analysis in Figure 1 showed that administration of additional convalescent plasma therapy for COVID-19 patients had a significant benefit in reducing mortality with risk ratio below $1(\mathrm{RR}=0,64)$, CI 95\% below $1[0,51-0,81]$, and p-value less than $0,05 \quad(p=0,0002)$. A random-effect model was used to analyze the literature due to high heterogeneity, interpreted from $\mathrm{I}^{2}$ more than $50 \%\left(\mathrm{I}^{2}=59 \%\right.$ and $\left.\mathrm{p}=0.009\right)$. Funnel plot analysis of all literature shown in patients with one comorbidity $(22.3 \%$ vs $36.5 \% ; \mathrm{p}=0.004$ $\mathrm{OR}=0.50,95 \%$ CI: $0.31-$ 0.80 ). Moreover, patients on ventilator had significantly lower mortality in the plasma $\operatorname{arm}(37.2 \%$ vs $49.3 \% ; \mathrm{p}=$ $0.009 ;$ OR $=0.61,95 \%$ CI: $0.42-0.89$ ); particularly so for patients on invasive mechanical ventilation $(63.9 \%$ vs $82.9 \%$; $\mathrm{p}=0.014$; $\mathrm{OR}=0.37,95 \%$ CI: $0.16-$ 0.83 ).

The analysis showed a significant reduction $(\mathrm{P}=$ 0.047 ) in mortality within 28
Figure 2 shows asymmetrical distribution, which indicates publication bias.

Another forest plot analysis was done with subgroups that classify works of literature based on study designs to identify the cause of data heterogeneity and whether the difference held significance for the results. The subgroups were "cohort" consisting of 5 literatures and "clinical trial" consisting of 4 literatures. The case-control literature was not classified into any subgroup as there was no available comparing literature. According to cohort subgroup, administration of additional convalescent plasma therapy for COVID-19 patients had significant benefit in reducing mortality with risk ratio below 1 $(\mathrm{RR}=0.53)$, CI 95\% below 1 [0.35-0.81], and $\mathrm{p}$-value less than $0.1(\mathrm{p}=0.003)$. 


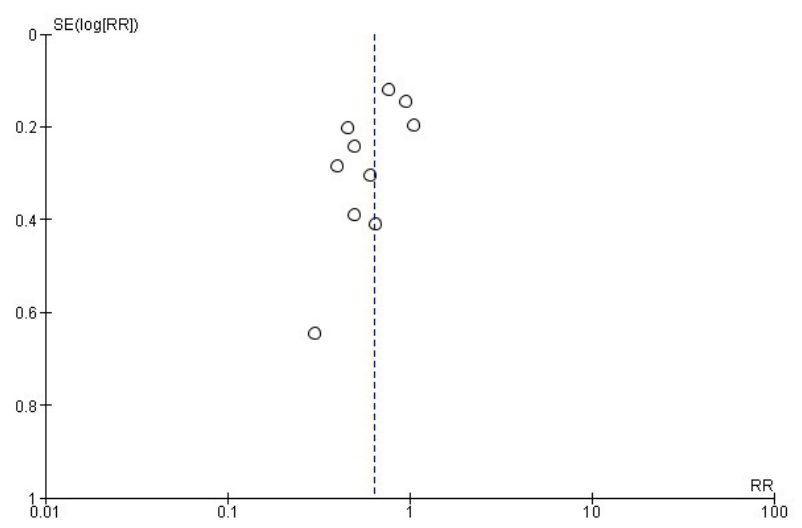

Figure 2. Funnel plot of all literature

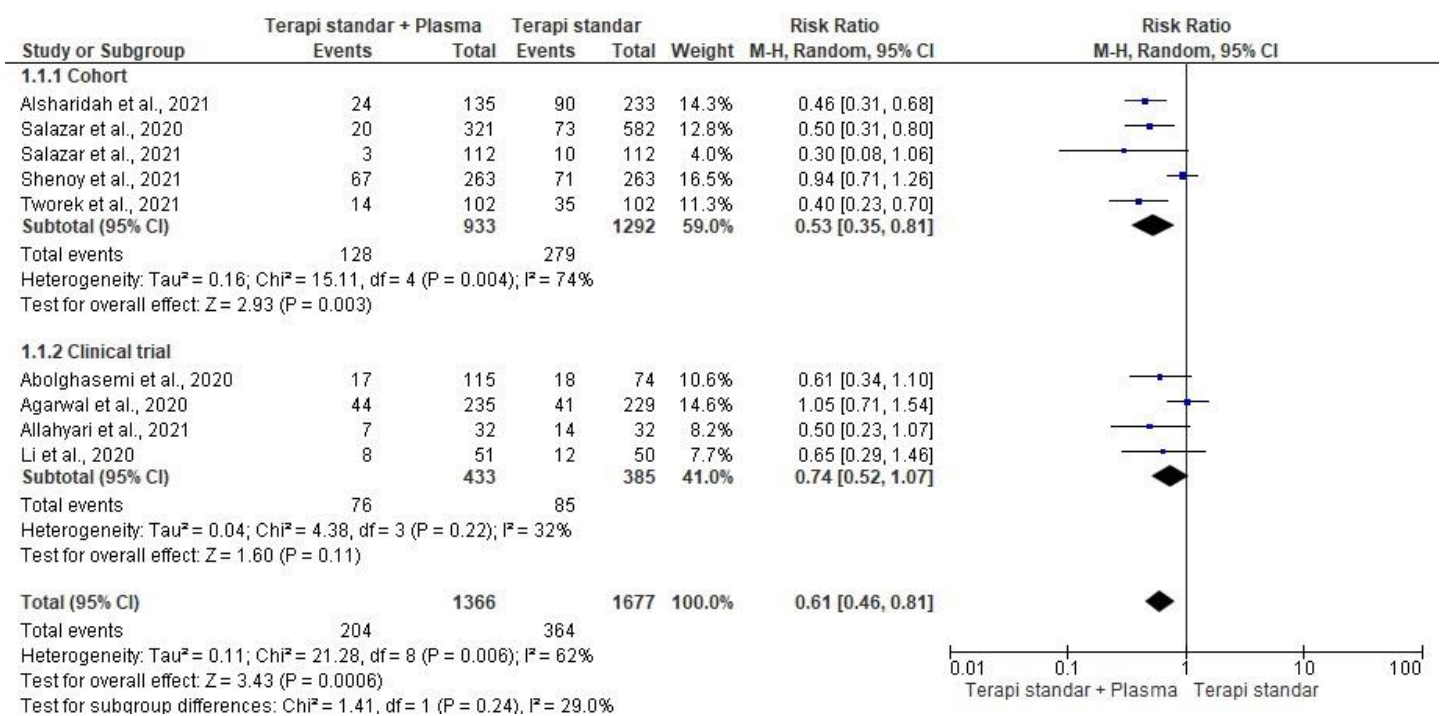

Figure 3. Forest plot after subgroup analysis

According to clinical trial subgroup, administration of additional convalescent plasma therapy for COVID-19 patients had no significant benefit in reducing mortality with risk ratio below $1(\mathrm{RR}=0.74), \mathrm{CI} 95 \%$ above 1 [0.52-1.07], and p-value more than $0.1(\mathrm{p}=0.11)$. The details of these results are shown in Figure 3.

Subgroup analysis for cohort study design showed high heterogeneity of $\mathrm{I}^{2}=74 \%$, so a leave-one-out sensitivity test was done. The exclusion of literature by Shenoy et al. caused a significant change in heterogeneity value into $\mathrm{I}^{2}=0 \% .^{9}$ The funnel plot after subgroup analysis in Figure 4 shows the asymmetrical distribution, which indicates publication bias.

\section{DISCUSSION}

Convalescent plasma therapy is an adjunct therapy in COVID-19 patients, reducing viral load, cytokine response, and mortality. In addition, convalescent plasma therapy also transfers antibodies of a specific infectious agent from a recovered person to a patient infected by the same disease agent. Passive immunity helps the patient to prevent the disease progression. ${ }^{15}$ 


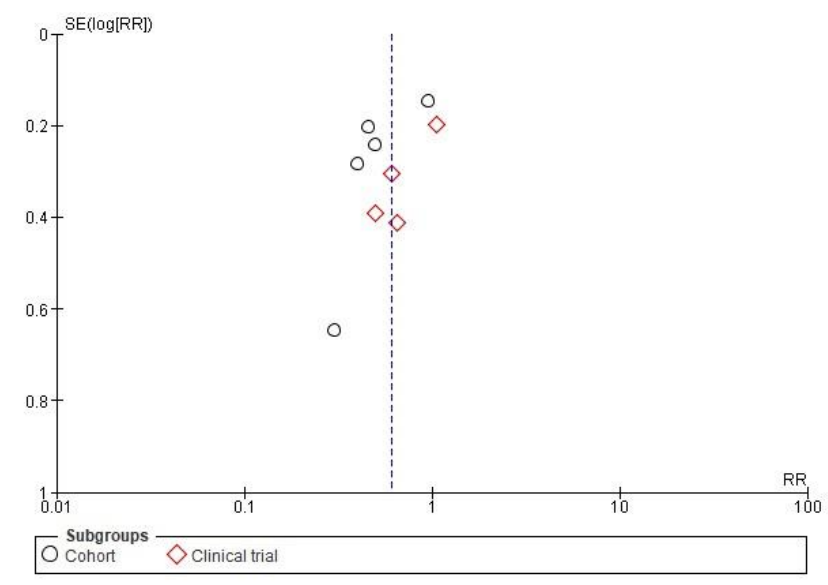

Figure 4. Funnel plot after subgroup analysis

Previous study by Xingsheng Hu et al. stated that convalescent plasma therapy was effective and safe. ${ }^{16}$ Patients showed clinical and laboratory improvements after receiving convalescent plasma therapy, characterized by increased respiratory function and decreased oxygen dependence. Patients who initially received high-flow nasal cannula oxygenation could switch to low-flow nasal cannula oxygenation. Other studies stated that convalescent plasma therapy was safe for COVID-19 patients even though the patient had poor prognostic criteria for severity and/or risk factors. ${ }^{17}$

In the overall meta-analysis study of 10 journals through forest plot, there was a significant difference between mortality in the convalescent plasma therapy group and standard therapy with the standard therapy only group. The mortality in a combination of convalescent plasma therapy group and standard therapy was lower than the mortality in standard therapy only. The results were under a study conducted on 204 COVID-19 patients, where 102 patients were given standard therapy only, and the remaining 102 were given the combination of standard therapy and convalescent plasma therapy. The study showed that the addition of convalescent plasma therapy significantly reduced the mortality of COVID-19 patients. $^{12}$ The results were also following a study conducted by Abolghasemi, et al., which stated that plasma therapy substantially improved patient survival, significantly reduced the length of stay, and the use of intubation in COVID-19 patients compared to the control group. ${ }^{7}$ Apart from several limitations, this clinical study provided strong evidence to support the efficacy of convalescent plasma therapy and therefore recommended the therapy as one of COVID-19 patients' management.

Another study also stated that convalescent plasma therapy could improve the resolution of shortness of breath and fatigue in patients with moderate COVID-19 and caused a higher conversion rate to negative SARSCoV-2 RNA on day 7, but death or disease progression could occur within 28 days death. ${ }^{6}$ These results could be affected by various factors, where different hospitals provided different standard therapies, the antibody titers were not measured due to limited resources.

Other studies also stated that a combination of convalescent plasma therapy and standard therapy provided insignificant 28-days clinical improvement for patients with severe or life-threatening COVID-19. However, the study was terminated early after recruiting 51 patients in the intervention group and 50 patients in the control group, which might have caused the inability to detect the 
significance of convalescent plasma therapy on the mortality of COVID-19 patients. $^{5}$

Ten research journals in this study were divided into several subgroups according to each study's type of study design. The subgroup consisted of a subgroup for cohort studies and a subgroup for clinical trial studies. This step aimed to determine the causes of the existing data's heterogeneity and determine whether these differences had significance to the current research results.

In the cohort subgroup meta-analysis, there was a significant difference between mortality in the combination of convalescent plasma therapy and the standard therapy group with the standard therapy only group. There was significant heterogeneity based on the forest plot data, so a sensitivity test was carried out, and the study by Shenoy, et al. was excluded. ${ }^{9}$ This test resulted in a significant change in data heterogeneity with previously $\mathrm{RR}=0.53,95 \% \mathrm{CI}[0.35-0.81], \mathrm{p}$ $=0.003$; and $\mathrm{I} 2=74 \%$ and $\mathrm{p}=0.004$ into $\mathrm{RR}$ $=0.45,95 \%$ CI [0.35-0.58], $\mathrm{p}<0.00001$; and $\mathrm{I} 2=0 \%$ and $\mathrm{p}=0.86$. The study by Shenoy, et al. (2021) explained that the combination group of convalescent plasma and standard therapy had a significant impact on mortality on the 7th and 14th-day evaluations but were not significant on the 28th day due to the presence of comorbid diseases that appeared later in the patient. In addition, there was a limitation due to the absence of data on convalescent plasma antibody titers given. For patients administered convalescent plasma with a low antibody titer, convalescent plasma could prevent the disease progression but did not suppress the replication or inflammatory processes.

There was no significant difference between mortality in the combination of convalescent plasma therapy and the standard therapy group with the standard therapy only group in the clinical trial subgroup meta-analysis. It is influenced by several factors, such as explanations on the study of Li et al. and the research of Agarwal et al. . $^{5,6}$
In the study conducted by Abolghasemi et al. (2020), the addition of convalescent plasma reduced the number of mortalities in COVID19 patients compared to patients treated with standard therapy only $(14.8 \%$ with the combination of standard therapy and convalescent plasma therapy and $24.3 \%$ with standard therapy only). The results were influenced by the number of COVID-19 patients in the control group, which was less $(\mathrm{n}=74)$ than the intervention group $(\mathrm{n}=$ 115), and the health workers specifically chose patients with milder symptoms and those without a plasma donor into the control group. Identical arguments regarding the factor which caused the insignificant results were also stated in the study conducted by Allahyari, et al. ${ }^{8}$

In this study, there was a significant difference between the mortality in the combination of convalescent plasma therapy and the standard therapy group with the standard therapy only group. However, this study has limitations as the research data collected has high heterogeneity. The results could be influenced by various factors such as the sample size, timing, dose, titer, the amount of convalescent plasma administered, and the different standard therapy protocols given by hospital institutions used in secondary data from this study. Therefore, further research is needed regarding the effectiveness of convalescent plasma therapy with standard therapy for COVID-19 patients.

\section{CONCLUSION}

From this study, it can be concluded that patients who received the combination of standard therapy and convalescent plasma therapy had lower mortality than those who only received standard therapy. However, results of the meta-analysis of the clinical trial sub-groups showed no significant differences between mortality in the group of COVID-19 patients who received a combination of standard therapy and convalescent plasma therapy with the group 
of COVID-19 patients who only received standard therapy. These results could be influenced by various factors such as the timing of convalescent plasma therapy, dose, titer, and the amount of convalescent plasma administered, and the different standard therapy protocols given by hospital institutions used in secondary data from secondary data this study.

\section{REFERENCES}

1. WHO (2021). Indonesia: WHO Coronavirus (COVID-19) Dashboard, https://covid19.who.int/region/searo/co untry/id (Accessed 25 April 2021)

2. NIH (2020). COVID-19 Treatment Guidelines Panel. Coronavirus Disease 2019 (COVID-19) Treatment Guidelines. National Institutes of Health

3. (PDPI) PDPI, (PERKI) PDSKI, (PAPDI) PDSPDI, et al (2020). Pedoman Tatalaksana COVID-19 edisi 2

4. RI K (2020). Gugus Tugas Percepatan Penanganan COVID-19, https://covid19.go.id/peta-sebaran

5. Li L, Zhang W, Hu Y, et al (2020). Effect of Convalescent Plasma Therapy on Time to Clinical Improvement in Patients With Severe and Lifethreatening COVID-19: A Randomized Clinical Trial. Jama, 324, 460-470. DOI: 10.1001/jama.2020.10044.

6. Agarwal A, Mukherjee A, Kumar G, et al (2020). Convalescent plasma in the management of moderate covid-19 in adults in India: open label phase II multicentre randomised controlled trial (PLACID Trial). Bmj, 371, m3939 DOI: 10.1136/bmj.m3939.

7. Abolghasemi H, Eshghi $\mathrm{P}$, Cheraghali AM, et al (2020). Clinical efficacy of convalescent plasma for treatment of COVID-19 infections: Results of a multicenter clinical study. Transfus Apher Sci, 59, 102875. DOI: 10.1016/j.transci.2020.102875.

8. Allahyari A, Seddigh-Shamsi M, Mahmoudi M, et al (2021). Efficacy and safety of convalescent plasma therapy in severe COVID-19 patients with acute respiratory distress syndrome. International immunopharmacology, 93, 107239-107239.

DOI: 10.1016/j.intimp.2020.107239.

9. Shenoy AG, Hettinger AZ, Fernandez SJ, et al (2021). Early mortality benefit with COVID-19 convalescent plasma: a matched control study. Br J Haematol, 192, 706-713. DOI: 10.1111/bjh.17272.

10. Salazar E, Christensen PA, Graviss EA, et al (2021). Significantly Decreased Mortality in a Large Cohort of Coronavirus Disease 2019 (COVID-19) Patients Transfused Early with Convalescent Plasma Containing HighTiter Anti-Severe Acute Respiratory Syndrome Coronavirus 2 (SARS-CoV2) Spike Protein IgG. The American journal of pathology, 191, 90-107

DOI: 10.1016/j.ajpath.2020.10.008.

11. Alsharidah S, Ayed M, Ameen RM, et al (2021). COVID-19 convalescent plasma treatment of moderate and severe cases of SARS-CoV-2 infection: A multicenter interventional study. Int $\mathrm{J}$ Infect Dis, 103: 439-446. 2020/12/08. DOI: $10.1016 /$ j.ijid.2020.11.198.

12. Tworek A, Jaroń K, Uszyńska-Kałuża B, et al (2021). Convalescent plasma treatment is associated with lower mortality and better outcomes in highrisk COVID-19 patients - propensityscore matched case-control study. Int J Infect Dis, 105, 209-215. DOI: 10.1016/j.ijid.2021.02.054.

13. Budhiraja S, Dewan A, Aggarwal R, et al (2021). Effectiveness of convalescent plasma in Indian patients with COVID19. Blood Cells Mol Dis, 88, 102548.

DOI: 10.1016/j.bcmd.2021.102548.

14. Salazar E, Christensen PA, Graviss EA, et al (2020). Treatment of Coronavirus Disease $2019 \quad$ Patients with Convalescent Plasma Reveals a Signal of Significantly Decreased Mortality. Am J Pathol, 190, 2290-2303. DOI: 10.1016/j.ajpath.2020.08.001.

15. Putera DD, Hardianti MS (2020). Efficacy and safety of convalescent 
plasma therapy in patients with COVID19: arapid review of case series. J Med Sci, 52(3), 134-147. DOI: 10.19106/JMedSciSI005203202012.

16. $\mathrm{Hu} \mathrm{X,} \mathrm{Hu} \mathrm{C,} \mathrm{Jiang} \mathrm{D,} \mathrm{et} \mathrm{al} \mathrm{(2020).}$ Effectiveness of Convalescent Plasma Therapy for COVID-19 Patients in Hunan, China. Dose-Response, 18, 1559325820979921.
DOI: $10.1177 / 1559325820979921$.

17. Gazitúa R, Briones JL, Selman C, et al (2020). Convalescent Plasma in COVID-19. Mortality-Safety First Results of the Prospective Multicenter FALP 001-2020 Trial. DOI:10.1101/2020.11.30.20218560. 